\title{
Identification of TYMS as a promoting factor of retroperitoneal liposarcoma progression: Bioinformatics analysis and biological evidence
}

\author{
SHA ZHANG ${ }^{1}$, LIANG YAN $^{1}$, CAN CUI $^{2}$, ZHEN WANG $^{1}$, JIANHUI WU $^{1}$, MIN ZHAO $^{3}$, \\ BIN DONG $^{4}$, XIAOYA GUAN ${ }^{1}$, XIUYUN TIAN ${ }^{1}$ and CHUNYI HAO ${ }^{1}$ \\ ${ }^{1}$ Key Laboratory of Carcinogenesis and Translational Research (Ministry of Education/Beijing), \\ Department of Hepato-Pancreato-Biliary Surgery, Peking University Cancer Hospital and Institute, Beijing 100142; \\ ${ }^{2}$ Department of Breast Oncology, Tianjin Medical University Cancer Institute and Hospital, Key Laboratory of Breast Cancer \\ Prevention and Therapy, Tianjin Medical University, Ministry of Education, Key Laboratory of Cancer Prevention and Therapy, \\ Tianjin 300060; ${ }^{3}$ Key Laboratory of Carcinogenesis and Translational Research (Ministry of Education/Beijing), Department of \\ Pathology; ${ }^{4}$ Key Laboratory of Carcinogenesis and Translational Research (Ministry of Education/Beijing), \\ Central Laboratory, Peking University Cancer Hospital and Institute, Beijing 100142, P.R. China
}

Received December 14, 2019; Accepted May 14, 2020

DOI: $10.3892 /$ or.2020.7635

\begin{abstract}
Retroperitoneal liposarcoma (RLPS) is one of the most common types of retroperitoneal sarcomas, and has a high recurrence rate. There is an urgent need to further explore its pathogenesis and develop more effective treatment strategies. The aim of the present study was to identify potential driver genes of RLPS through bioinformatics analysis and molecular biology to elucidate potential targets that are suitable for further analysis for the treatment of RLPS. Differentially expressed genes (DEGs) between liposarcoma and normal fatty (NF) tissues were identified based on microarray data through bioinformatics analysis, and thymidylate synthase (TYMS) was selected from the DEGs, based on high content screening (HCS). TYMS expression was evaluated in RLPS tumor tissues and cell lines. A total of 21
\end{abstract}

Correspondence to: Professor Xiuyun Tian or Professor Chunyi Hao, Key Laboratory of Carcinogenesis and Translational Research (Ministry of Education/Beijing), Department of Hepato-Pancreato-Biliary Surgery, Peking University Cancer Hospital and Institute, 52 Fucheng Road, Haidian, Beijing 100142, P.R. China

E-mail: xiuyunt@126.com

E-mail: haochunyi@bjmu.edu.cn

Abbreviations: DEG, differentially expressed gene; DFS, disease-free survival; HCS, high content screening; JAK/STAT, Janus kinase/signal transducers and activators of transcription; NF, normal fatty; OS, overall survival; RLPS, retroperitoneal liposarcoma; RPS, retroperitoneal soft tissue sarcoma; TYMS, thymidylate synthase

Key words: RLPS, DEG, TYMS, tumor progression, JAK/STAT
RLPS tissues and 10 NF frozen tissues were used for reverse transcription-quantitative PCR, and 47 RLPS formalin-fixed specimens were used for immunohistochemical analysis. The effect of TYMS downregulation on cell proliferation, apoptosis, cell cycle progression, and cell migration and invasion were evaluated using lentivirus-mediated short hairpin RNA. The underlying mechanisms of TYMS in RLPS were examined by protein microarray and verified by western blotting. A total of 855 DEGs were identified. TYMS knockdown had the most notable effect on the proliferative capacity of RLPS cells according to the HCS results. TYMS mRNA expression levels were higher in RLPS tissues compared with NF tissues $(\mathrm{P}<0.001)$. TYMS expression was higher in high-grade RLPS tissues compared with low-grade RLPS tissues $(\mathrm{P}=0.003)$. The patients with positive TYMS expression had a worse overall survival (OS) and disease-free survival (DFS) compared with the patients with negative TYMS expression $(\mathrm{OS}, \mathrm{P}=0.024$; DFS, $\mathrm{P}=0.030$ ). The knockdown of TYMS reduced proliferation, promoted apoptosis, facilitated cell cycle progression from $\mathrm{G}_{1}$ to $\mathrm{S}$ phase, and reduced cell migration and invasion of RLPS cells. Protein microarray analysis and western blotting showed that the Janus Kinase/Signal transducers and activators of transcription pathway was downregulated following TYMS knockdown. In conclusion, TYMS expression is upregulated in RLPS tissues, and downregulation of TYMS reduces RLPS progression.

\section{Introduction}

Retroperitoneal soft tissue sarcoma (RPS) is a rare type of tumor, accounting for $12-15 \%$ of all soft tissue sarcomas and $1 \%$ of all solid tumors, with an average incidence rate of 2.7 cases per million individuals in the United States in 2005 (1). Retroperitoneal liposarcoma (RLPS) is the most common type of retroperitoneal soft tissue sarcoma, accounting for $45 \%$ of 
RPS cases and $0.07-0.2 \%$ of all tumors (2). Chemoradiotherapy has a limited effect on RLPS, and surgical resection is the most effective treatment for RLPS (3). However, it is difficult to achieve complete surgical resection and local recurrence is common (4-6). Therefore, it is essential to identify the regulatory factors and to further elucidate the mechanisms underlying RLPS progression, to assist in the development of effective interventions.

Gene expression analysis of microarrays is a useful method to extensively examine the pathogenesis of diseases by investigating the differences in gene expression and the activity of functional signaling pathways between patients and healthy donors using bioinformatics analysis, which may highlight potential targets for treatment of various diseases (7-9). High content screening (HCS) is a high-throughput process for automatic analysis of biological behaviors such as proliferation and for identification of drug targets (10).

In the present study, the aforementioned two methods were combined to facilitate the selection of therapeutic targets. Specifically, potential driver genes of LPS were identified using bioinformatics analysis based on the results of a microarray performed by Barretina et al (11). Furthermore, the effects of the identified genes on biological behavior was assessed using HCS to elucidate potential markers for use in future targeted therapies.

\section{Materials and methods}

Microarray data. The Gene Expression Omnibus (GEO) (https://www.ncbi.nlm.nih.gov/pmc/) is an open database, which provides high-throughput data for biological research. The GSE21122 dataset is based on the Affymetrix Human Genome U133A Array (HG-U133A) GPL96 platform and includes a variety of soft-tissue sarcoma specimens (11). The dataset contained data on 89 liposarcoma specimens (46 dedifferentiated liposarcoma specimens, 20 myxoid liposarcoma specimens and 23 pleomorphic liposarcoma specimens) and 9 NF specimens, which were downloaded for further analysis.

Data processing and identification of differentially expressed genes (DEGs). The original file was parsed to obtain the signal intensity of each probe. The dataset and the signal intensity values of each probe set were acquired using the robust multi-array average algorithm (12). Due to the design principle of the chip itself, and the artificial or other unavoidable factors in the experimental process, there were a large number of unqualified or invalid detection points in the chip raw data. The probe sets in the lowest $20 \%$ of the signal intensity order of all the probe sets in the two sample groups were filtered and considered as background noise. Subsequently, the variable coefficient of the same probe group in the same sample group was calculated using the coefficient of variation method (a method for comparing the discreteness of two sets of data), and the probe groups with a coefficient of variation $>25 \%$ in both groups were filtered out. The limma package in $\mathrm{R}$ v3.4.3 (13) was used to identify DEGs and a linear model based on the empirical Bayesian distribution was used to calculate the significant difference level (P-value). The Benjamini-Hochberg method (14) was used to correct the significant difference level and to obtain the false discovery rate (FDR). An FDR $<0.05$ and $\mid \log \mathrm{FCl}>1$ were used as the cut-off criteria for DEGs, wherein a $\log \mathrm{FCl}<0$ was considered as a downregulated gene and a $\mid \log \mathrm{FCl}>0$ was considered as an upregulated gene. The volcano map and heatmap were developed using the ggplot 2 package and pheatmap package in $\mathrm{R}$ version 3.4.3, respectively (15).

$R N A$ extraction and reverse transcription quantitative-PCR $(R T-q P C R)$. Total RNA was extracted from cell lines and frozen tissues using TRIzol ${ }^{\circledR}$ reagent (cat. no. 15596026; Thermo Fisher Scientific, Inc.) according to the manufacturer's protocol. RT was performed using 5X All-In-One RT MasterMix kit (cat. no. G490; Applied Biological Materials, Inc.) according to the manufacturer's instruction. The procedure for RT was: $25^{\circ} \mathrm{C}$ for $10 \mathrm{~min}, 42^{\circ} \mathrm{C}$ for $15 \mathrm{~min}$ and $85^{\circ} \mathrm{C}$ for 5 min. qPCR was performed using EvaGreen $2 \mathrm{X}$ qPCR MasterMix (cat. no. Master Mix-LR; Applied Biological Materials, Inc.) on an ABI 7500 fast real-time PCR Detection system (Thermo Fisher Scientific, Inc.) according to the manufacturer's protocol. The thermocycling conditions for qPCR were: Pre-denaturation at $95^{\circ} \mathrm{C}$ for $10 \mathrm{~min}$; followed by 40 cycles of denaturation at $95^{\circ} \mathrm{C}$ for $15 \mathrm{sec}$, annealing at $60^{\circ} \mathrm{C}$ for $1 \mathrm{~min}$ and extension at $72^{\circ} \mathrm{C}$ for $30 \mathrm{sec}$. Primers were designed with Primer v6.0 (Thermo Fisher Scientific, Inc.). GAPDH was used as an internal reference gene. All reactions were performed in triplicate. The specificity of qPCR was confirmed by melting-curve analysis. The relative expression was calculated and analyzed using the $2^{-\Delta \Delta \mathrm{Cq}}$ method (16). The primer sequences are shown in Table SI.

Screening of genes that affect cell proliferation based on the HCS method. Short hairpin RNA (shRNA) was used to construct the gene knockdown vector (cat. no. GV115; Shanghai GeneChem Co., Ltd.). Three RNA interference targets were designed for each gene (Table SII), and three plasmids carrying different targets were mixed in equal proportions for lentivirus packaging. The 94T778 cells were infected with lentivirus containing the shRNAs using X-tremeGENE HP DNA Transf. Reag. $1.0 \mathrm{ml}$ (cat. no. 6366236001; Roche Pharmaceutical, Ltd.). The cells were imaged using a Celigo ${ }^{\circledR}$ Image Cytometer (Nexcelom Bioscience) with a fluorescence microscope. For each experimental well of a 96-well plate, Celigo ${ }^{\circledR}$ Image Cytometer scanned four fields of view at each time point (magnification, $x 40$ ), and the cells were counted in the images with the corresponding analysis software in the Celigo ${ }^{\circledR}$ Image Cytometer to obtain the number of cells in the experimental well.

Patients and samples. All specimens of RLPS and NF tissues were obtained from patients who underwent surgical resection between March 2015 and January 2018 at the Peking University Cancer Hospital Sarcoma Center (Beijing, China). None of the patients received chemotherapy or radiotherapy prior to surgery. A total of 47 RLPS tissues (from 27 males and 20 females, with age range between 20 and 80 years, and the mean age was $55.3 \pm 10.7$ years) were formalin-fixed immediately after resection, and embedded in paraffin prior to immunohistochemical analysis. The detailed clinicopathological characteristics of the 47 patients with RLPS are presented in Table I. The histopathological analysis of tumor tissues was performed by two pathologists, independently. 
Table I. Clinicopathological characteristics of the 47 patients with RLPS.

\begin{tabular}{|c|c|}
\hline Clinicopathological characteristics & $\mathrm{N}(\%)$ \\
\hline \multicolumn{2}{|l|}{ Sex } \\
\hline Male & $27(57.4)$ \\
\hline Female & $20(42.6)$ \\
\hline \multicolumn{2}{|l|}{ Age, years } \\
\hline$<55$ & $31(66.0)$ \\
\hline$\geq 55$ & $16(34.0)$ \\
\hline \multicolumn{2}{|l|}{ Tumor number } \\
\hline Single & $37(78.7)$ \\
\hline Multiple & $10(21.3)$ \\
\hline \multicolumn{2}{|l|}{ Tumor size, $\mathrm{cm}$} \\
\hline$<15$ & 7 (14.9) \\
\hline $15-30$ & $26(55.3)$ \\
\hline$\geq 30$ & $14(29.8)$ \\
\hline \multicolumn{2}{|l|}{ Histological subtype $^{a}$} \\
\hline Well-differentiated & $14(29.8)$ \\
\hline Dedifferentiated & $23(48.9)$ \\
\hline Myxoid/round cell & $5(10.6)$ \\
\hline Pleomorphic & $5(10.6)$ \\
\hline \multicolumn{2}{|l|}{ Grade $^{\mathrm{b}}$} \\
\hline Low-grade & $14(29.8)$ \\
\hline High-grade & $33(70.2)$ \\
\hline
\end{tabular}

For qPCR, 21 RLPS tissues (12 males and 9 females, the mean age was $55.0 \pm 8.5$ years old) and $10 \mathrm{NF}$ tissues (6 males and 4 females, the mean age was $57.4 \pm 8.4$ years old) were snap-frozen in liquid nitrogen immediately after resection and transferred to $-80^{\circ} \mathrm{C}$ freezer for long-term storage. The present study was approved by the Ethics Committee of Peking University Cancer Hospital (approval no. 2019KT19) and written informed consent was obtained from each participant.

Immunohistochemistry (IHC). The 4- $\mu$ m-thick slices were heated for $1 \mathrm{~h}$ at $72^{\circ} \mathrm{C}$ and then dewaxed in xylene (cat. no. 10023418; Sinopharm Chemical Reagent Co., Ltd.) for $30 \mathrm{~min}$ at room temperature, and hydrated in 100,95 and $85 \%$ ethanol solutions (cat. no. 10009259; Sinopharm Chemical Reagent Co., Ltd.) for $5 \mathrm{~min}$ at room temperature, respectively. The slices were incubated in 3\% hydrogen peroxide for $15 \mathrm{~min}$ at room temperature to block endogenous peroxidase activity. Heat-mediated antigen retrieval was performed using EDTA buffer (cat. no. ZLI-9069; pH=9.0; OriGene Technologies, Inc.), after the pressure valve of the pressure cooker is exhausted for the first time, the firepower is reduce and the high pressure is continue for $2 \mathrm{~min}$ and $30 \mathrm{sec}$. Goat serum (cat. no. ZLI-9056; OriGene Technologies, Inc.) was used to block slices at $37^{\circ} \mathrm{C}$ for $1 \mathrm{~h}$, after cooling to room temperature.
Subsequently, the slices were incubated with the thymidylate synthase (TYMS) antibody (1:100; cat. no. ab108995; Abcam) overnight at $4^{\circ} \mathrm{C}$. The following day, the slices were incubated with the goat anti-mouse/rabbit IgG-HRP conjugated antibody secondary antibody (at working solution; cat. no. PV-6000; OriGene Technologies, Inc.). The slices were visualized at room temperature using DAB (Dako; Agilent Technologies, Inc.) containing hydrogen peroxide for staining specific protein, when the specific staining is strong and the background color is shallow, the slice can be washed, and then using hematoxylin (cat. no. HK100-9K; Biogenex) for staining nucleus for $1 \mathrm{~min}$ at room temperature. Following TYMS staining, semi-quantitative classification of TYMS staining was performed according to the percentage of positive cells (PP) and staining intensity (SI) by two pathologists, who were blinded to the clinical information. The PP was scored as: 0 , negative; $1,<25 ; 2,25-75 \%$; and $3,>75 \%$. SI was scored as: 0 , negative; 1 , weak; 2 , moderate; and 3 , strong. The immunoreactivity score (IRS) was defined as PP multiplied by SI, where IRS $=0$ was considered as 'negative', and IRS $>0$ was considered as 'positive'.

Survival analysis. Gene Expression Profiling Interactive Analysis (GEPIA) database (http://gepia.cancer-pku. $\mathrm{cn} /$ ?from=timeline\&isappinstalled $=0$ ) was used to analyze the association between TYMS expression and the overall survival (OS) and disease-free survival (DFS) of patients with sarcoma.

Cell lines and cell culture. The human RLPS cell lines 93T449, 94T778 and SW872 were purchased from American Type Culture Collection and cultured in RPMI-1640 medium (Gibco; Thermo Fisher Scientific, Inc.) containing 10\% FBS, $100 \mu \mathrm{g} / \mathrm{ml}$ penicillin, and $100 \mu \mathrm{g} / \mathrm{ml}$ streptomycin. Cells were maintained in a humidified incubator at $37^{\circ} \mathrm{C}$ with $5 \% \mathrm{CO}_{2}$.

Western blot analysis. Total protein was extracted using RIPA lysis buffer (cat. no. CW2333S; CWBIO) and supplemented with a protease and phosphatase inhibitor cocktail (cat. nos. CW2200S and CW2383S; CWBIO). A BCA Protein assay kit (cat. no. CW0014S; CWBIO) was used to quantify extracted proteins. Equivalent quantities of protein $(5 \mu \mathrm{g})$ were separated by 8 or $10 \%$ SDS-PAGE and then transferred onto PVDF membranes. The membranes were blocked with $5 \%$ skimmed milk for $1 \mathrm{~h}$ at room temperature and then incubated with a series of primary antibodies at $4^{\circ} \mathrm{C}$ overnight. The following day, the membranes were incubated with secondary anti-rabbit or anti-mouse antibody for $1 \mathrm{~h}$ at room temperature. For detection of protein bands, Immobilon Western HRP Substrate Luminol Reagent (cat. no. WBKLS0500; EMD Millipore) and an enhanced chemiluminescence detection system (Amersham Imager 600; GE Healthcare) were used. The loading control used was $\beta$-actin. Image $\mathbf{J}$ software version 1.8.0 (National Institutes of Health) was used to analyze the intensities of western blot bands for the phosphorylated and non-phosphorylated proteins. All primary and secondary antibodies are listed in Table SIII.

Immunofluorescence staining. All three cell lines were seeded ( $3.5 \times 10^{5}$ for $93 \mathrm{~T} 449$ cells; $1.5 \times 10^{5}$ for $94 \mathrm{~T} 778$ cells; $3.0 \times 10^{5}$ for 
SW872 cells) on tissue culture (TC)-treated glass coverslips (cat. no. YA0351; Beijing Solarbio Science \& Technology Co., Ltd.) for $24 \mathrm{~h}$, then fixed with $4 \%$ paraformaldehyde for $20 \mathrm{~min}$ at room temperature, and incubated with a TYMS antibody (1:50; cat. no. 9045; Cell Signaling Technology, Inc.) at $4^{\circ} \mathrm{C}$ overnight. After washing, the cells were incubated with the goat anti-rabbit IgG-FITC conjugated antibody (1:100; cat. no. ZF-0311; OriGene Technologies, Inc.) for $30 \mathrm{~min}$ at room temperature, and the nucleus was stained with DAPI solution in the dark for $10 \mathrm{~min}$ at room temperature $(0.5 \mu \mathrm{g} / \mathrm{ml}$; cat no. D523; Dojindo Molecular Technologies, Inc.). Images were acquired using a Multiphoton Laser Scanning Microscope (magnification, x630; LSM780; Carl Zeiss Inc.).

shRNA-mediated knockdown of TYMS. shRNA, targeting TYMS, was constructed, packaged and purified by Shanghai GeneChem Co., Ltd. The lentiviral vector (cat. no. GV493; Shanghai GeneChem Co., Ltd.) containing non-silencing shRNA (Lenti-shCtrl) was used as the negative control. The stably transfected cells were selected using $1 \mu \mathrm{g} / \mathrm{ml}$ puromycin for $93 \mathrm{~T} 449$ and $94 \mathrm{~T} 778$, and $2 \mu \mathrm{g} / \mathrm{ml}$ puromycin for SW872. After lentivirus infection for $72-96 \mathrm{~h}$, and screening by puromycin for $48 \mathrm{~h}$, the cells were used for subsequent experiments. The efficiency of knockdown was confirmed using qPCR and western blot analysis.

Cell proliferation assay. A Cell Counting Kit-8 (CCK-8; Dojindo Molecular Technologies, Inc.) assay was performed to evaluate cell proliferation. Cells were plated in 96-well plates $\left(3 \times 10^{3}\right.$ per well for $93 \mathrm{~T} 449 ; 1.5 \times 10^{3}$ per well for $94 \mathrm{~T} 778$ and SW872 cells), $10 \mu$ of CCK-8 solution was added to each well, followed by the measurement of absorbance at $450 \mathrm{~nm}$ using a microplate reader (iMark; Bio-Rad Laboratories, Inc.) after $24,48,72,96$ or $120 \mathrm{~h}$.

Colony-formation assay. Cells were plated in 6-well plates at a density of 300 cells per well. The cells were cultured at $37^{\circ} \mathrm{C}$ for three weeks. Subsequently, colonies were fixed with $4 \%$ paraformaldehyde (cat. no. P1110; Beijing Solarbio Science $\&$ Technology Co., Ltd.) for $20 \mathrm{~min}$ at room temperature and stained with $0.1 \%$ crystal violet for 15 min (cat. no. G1063; Beijing Solarbio Science \& Technology Co., Ltd.) at room temperature. The number of colonies were imaged and counted using the Promega Colony Counter software version 10 (Promega Corporation).

TUNEL assay for cell apoptosis analysis. All three cell lines were cultured on 96-well plates $\left(4.0 \times 10^{4}\right.$ cells per well for 93T449; $2.0 \times 10^{4}$ cells per well for $94 \mathrm{~T} 778 ; 3.0 \times 10^{4}$ cells per well for SW872) for $24 \mathrm{~h}$, then fixed with $4 \%$ paraformaldehyde (as aforementioned), and subjected to cell apoptosis analysis using a TUNEL cell apoptosis assay kit (cat. no. T2190; Beijing Solarbio Science \& Technology Co., Ltd.) according to the manufacturer's protocol. The nucleus was stained using DAPI solution $(0.5 \mu \mathrm{g} / \mathrm{ml}$; cat. no. D523; Dojindo Molecular Technologies, Inc.) in the dark for $10 \mathrm{~min}$ at room temperature, and images were acquired using a Multiphoton Laser Scanning Microscope (magnification, x630; LSM780; Carl Zeiss Inc.). The number of TUNEL-positive cells were counted using the Promega Colony Counter software version 10 (Promega Corporation).
Cell cycle analysis. Cells were collected for cell cycle analysis. First, cells were digested with trypsin and washed with PBS, followed by overnight fixation at $4{ }^{\circ} \mathrm{C}$ with $75 \%$ ice-cold ethanol. On the second day, the fixed cells were centrifuged at $250 \mathrm{x}$ g, and washed with PBS at room temperature, followed by incubation for $15 \mathrm{~min}$ at room temperature in the dark with 300-500 $\mu \mathrm{l} \mathrm{PI/RNase} \mathrm{Staining} \mathrm{Buffer} \mathrm{(cat.} \mathrm{no.} \mathrm{550825;} \mathrm{BD}$ Pharmingen; BD Biosciences). BD Accuri C6 flow cytometry (Becton, Dickinson and Company) was used for cell collection and the ModFit LT software version 3.2 (Verity Software House, Inc.) was used for cell cycle analysis of the samples.

Migration and invasion assays. In the migration and invasion assays, chambers (migration assay, cat. no. 3422; invasion assay, cat. no. 354480; Corning, Inc.) were hydrated in serum-free RPMI-1640 medium (Gibco; Thermo Fisher Scientific, Inc.) for at least $2 \mathrm{~h}$ at $37^{\circ} \mathrm{C}$. A total of $1 \times 10^{5} 93 \mathrm{~T} 449$ cells, $3 \times 10^{4} 94 \mathrm{~T} 778$ cells or $3 \times 10^{4} \mathrm{SW} 872$ cells were mixed in serum-free medium with a total volume of $200 \mu \mathrm{l}$ for migration or $500 \mu \mathrm{l}$ for invasion. Cells were added to the upper chamber, and $500 \mu 1$ RPMI-1640 medium, containing 20\% FBS, was added to the lower compartment of the chamber. After $24 \mathrm{~h}$ of incubation for migration and $48 \mathrm{~h}$ for invasion, the cells in the upper chamber were removed. The cells that had invaded/migrated were fixed with $4 \%$ paraformaldehyde for $20 \mathrm{~min}$ at room temperature and stained with $0.1 \%$ crystal violet for $15 \mathrm{~min}$ at room temperature. The stained cells were imaged in five randomly selected fields using an optical microscope (magnification, $\mathrm{x} 400$ ), and the number of cells was calculated using ImageJ version 1.52t (National Institutes of Health).

Protein microarray analysis. Protein microarray analysis was performed using a Proteome Profiler ${ }^{\mathrm{TM}}$ Array-Human Phospho-Kinase Array kit (cat. no. ARY003B; R\&D Systems, Inc.) according to the manufacturer's protocol.

Statistical analysis. Statistical analysis was performed using SPSS version 20.0 (IBM Corp.) and GraphPad Prism version 7.0 (GraphPad Software, Inc.). A two-tailed $\chi^{2}$ test and Fisher's exact test were used to evaluate the association between TYMS expression and clinicopathological characteristics of patients with RLPS. Survival analysis was performed using Kaplan-Meier survival analysis and a log-rank test. An independent samples t-test was performed to compare two groups of quantitative data, and one-way ANOVAs with post-hoc Tukey's tests was performed to compare multiple groups of quantitative data. Results are presented as the mean \pm standard deviation. $\mathrm{P}<0.05$ was considered to indicate a statistically significant difference.

\section{Results}

Identification of DEGs in LPS. The microarray data of GSE21122 contained 89 LPS samples and 9 NF samples. The cut-off criteria for a gene to be considered as significantly differentially expressed were an FDR $<0.05$ and $\mid \log \mathrm{FCl}>1$. A total of 855 DEGs were extracted from GSE21122, of which 334 genes were upregulated and 521 genes were downregulated (Fig. S1; Table SIV). Fig. 1A shows the expression of DEGs in 

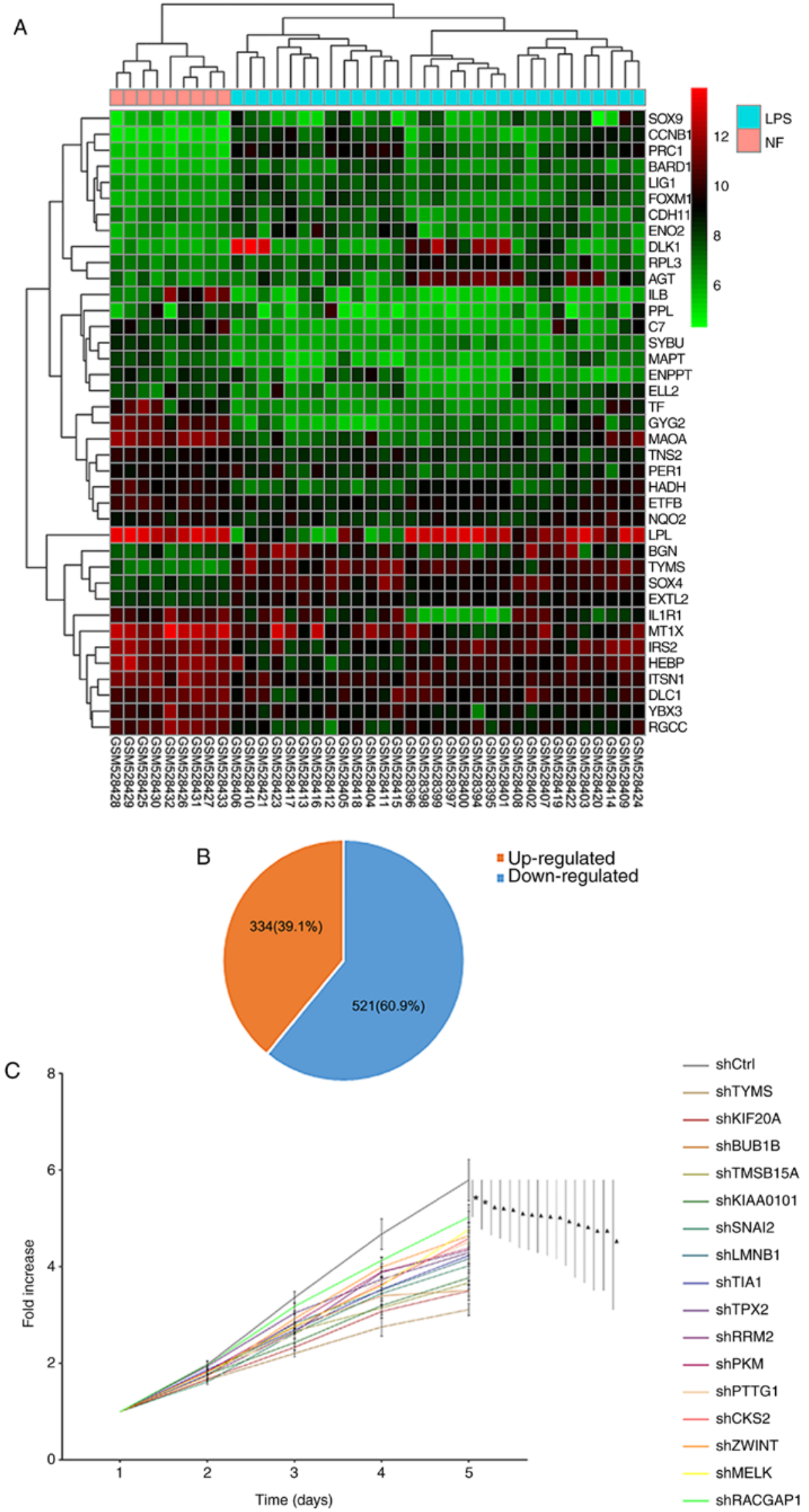

Figure 1. DEGs identified between LPS and NF samples and the functional genes screened from RLPS cells. (A) Representative heatmap of DEGs between LPS and NF samples. Hierarchical clustering analysis was performed using the expression profiles of DEGs with $\mid \log$ FCl $>1$ and an FDR $<0.05$. Each column represents a sample, and each row represents a DEG. Red, green and black indicate that the expression levels of the gene was upregulated, downregulated or was not significantly changed, respectively. (B) Percentage of upregulated and downregulated DEGs. (C) Suppression of 16 genes resulted in decreased proliferation of $94 \mathrm{~T} 778$ cell. The results are presented as the fold increase in cell growth relative to the first day. Cell proliferation was determined using the high content screening method. After the target genes were knocked down, cells exhibited reduced proliferative capacity compared with the control cells. ${ }^{*} \mathrm{P}<0.05$. ${ }^{\wedge} \mathrm{P}<0.001$. DEG, differentially expressed gene; FDR, false discovery rate; LPS, liposarcoma; NF, normal fatty; FC, fold change; sh, short hairpin. 
Table II. Association between TYMS expression and clinicopathological characteristics of patients with RLPS.

\begin{tabular}{|c|c|c|c|}
\hline Clinicopathological characteristics & Positive (\%) & Negative (\%) & P-value \\
\hline Sex & & & 0.154 \\
\hline Male & $18(66.7)$ & $9(33.3)$ & \\
\hline Female & $17(85.0)$ & $3(15.0)$ & \\
\hline Age, years & & & 0.505 \\
\hline$<55$ & $22(71.0)$ & $9(29.0)$ & \\
\hline$\geq 55$ & $13(81.2)$ & $3(18.8)$ & \\
\hline Tumor number & & & 0.700 \\
\hline Single & $28(75.7)$ & $9(24.3)$ & \\
\hline Multiple & $7(70.0)$ & $3(30.0)$ & \\
\hline Tumor size, $\mathrm{cm}$ & & & 0.723 \\
\hline$<15$ & $6(85.7)$ & $1(14.3)$ & \\
\hline $15-30$ & $18(69.2)$ & $8(30.8)$ & \\
\hline$\geq 0$ & $11(78.6)$ & $3(21.4)$ & \\
\hline Histological subtype & & & 0.009 \\
\hline Well-differentiated & $6(42.9)$ & $8(57.1)$ & \\
\hline Dedifferentiated & $21(91.3)$ & $2(8.7)$ & \\
\hline Myxoid/Round cell & $4(80.0)$ & $1(20.0)$ & \\
\hline Pleomorphic & $4(80.0)$ & $1(20.0)$ & \\
\hline Grade & & & 0.003 \\
\hline Low-grade & $6(42.9)$ & $8(57.1)$ & \\
\hline High-grade & $29(87.9)$ & $4(12.1)$ & \\
\hline
\end{tabular}

TYMS, thymidylate synthase.

LPS and NF samples, and Fig. 1B shows the percentage of upregulated and downregulated genes.

Gene expression in RLPS cells. To screen for functional genes which promoted the occurrence of RLPS, RT-qPCR was used to determine the expression of 40 genes that were considered to be upregulated in the RLPS cell line, 94T778, none of which have been previously studied in RLPS, to the best of our knowledge (Table SV). In 94T778 cells, 30 of the 40 examined genes exhibited higher expression compared with the other 10 genes (Table SVI), suggesting that expression of these 30 genes was relatively high in $94 \mathrm{~T} 778$ cells and were thus more likely to serve a role in the development of RLPS.

Knockdown of 16 genes significantly reduces proliferation of $94 T 778$ cells. Lentivirus-mediated shRNA was used to infect 94T778 cells and knockdown the 30 genes with high expression. Subsequently, the effect of these genes on proliferation of 94T778 cells was evaluated using the HCS method. The results showed that following knockdown, 16 of the 30 genes, including TYMS, KIF20A, BUB1B, TMSB15A, KIAA0101, SNAI2, LMNB1, TIA1, TPX2, RRM2, PKM, PTTG1, CKS2, ZWINT, MELK and RACGAP1, significantly slowed down the proliferation of 94T778 cells (Table SVII; Fig. 1C). Based on the results of HCS, knockdown of the TYMS gene had the most notable effect on the proliferative capacity of RLPS cells, and thus was selected to further explore its effect on the biological behaviors and the potential mechanisms involved in RLPS cells.
Expression of TYMS in RLPS tissues. mRNA expression of TYMS in 21 RLPS tissues and 10 NF tissues was assessed using qPCR. Relative mRNA expression of TYMS was notably higher in RLPS tissues compared with the NF tissues $(\mathrm{P}<0.001$; Fig. S2A). Furthermore, in the immunohistochemical assay, TYMS was expressed in 35 of the 47 RLPS tissues (74.5\%). IHC showed that TYMS was predominantly localized in the cytoplasm (Fig. S2B).

Association of TYMS expression with clinicopathological characteristics and survival of patients with RLPS. As shown in Table II, TYMS expression was 42.9, 91.3, 80.0 and $80.0 \%$ positive in well-differentiated, dedifferentiated, myxoid/round cell and pleomorphic subtypes, respectively $(\mathrm{P}=0.009)$. TYMS expression was significantly higher in patients with high-grade RLPS compared with patients with low-grade RLPS (low-grade vs. high-grade: $42.9 \%$ vs. $87.9 \%$; $\mathrm{P}=0.003$ ).

In the survival analysis, five patients were lost to follow-up, and in the remaining 42 cases, the median OS time was $29.21 \pm 24.68$ months in the TYMS-positive patients and $38.72 \pm 10.16$ months in TYMS-negative patients. The median DFS was $26.20 \pm 23.53$ months in TYMS-positive patients and $35.58 \pm 9.83$ months in TYMS-negative patients. Kaplan-Meier survival analysis and a log-rank test showed that TYMS expression was negatively associated with both OS and DFS time of patients with RLPS (Fig. S2C and D; OS, P=0.024; DFS, $\mathrm{P}=0.030)$. Furthermore, survival analysis of TYMS and sarcoma using GEPIA database showed that patients 

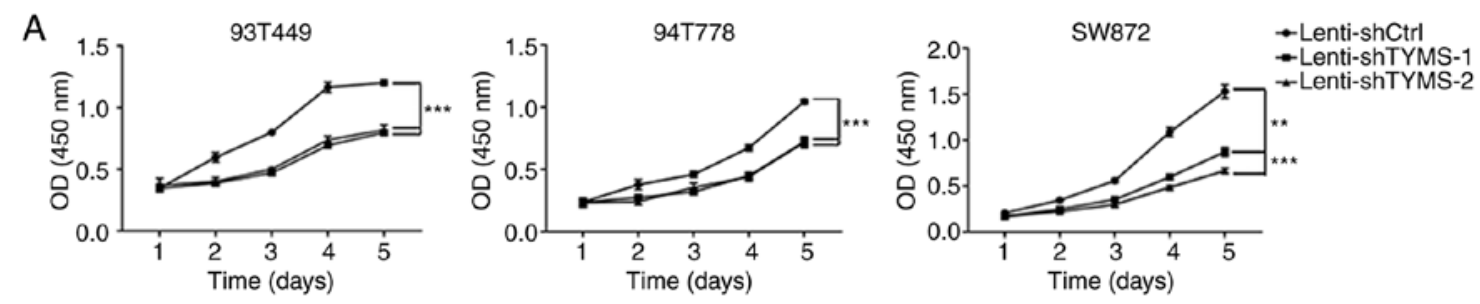

B
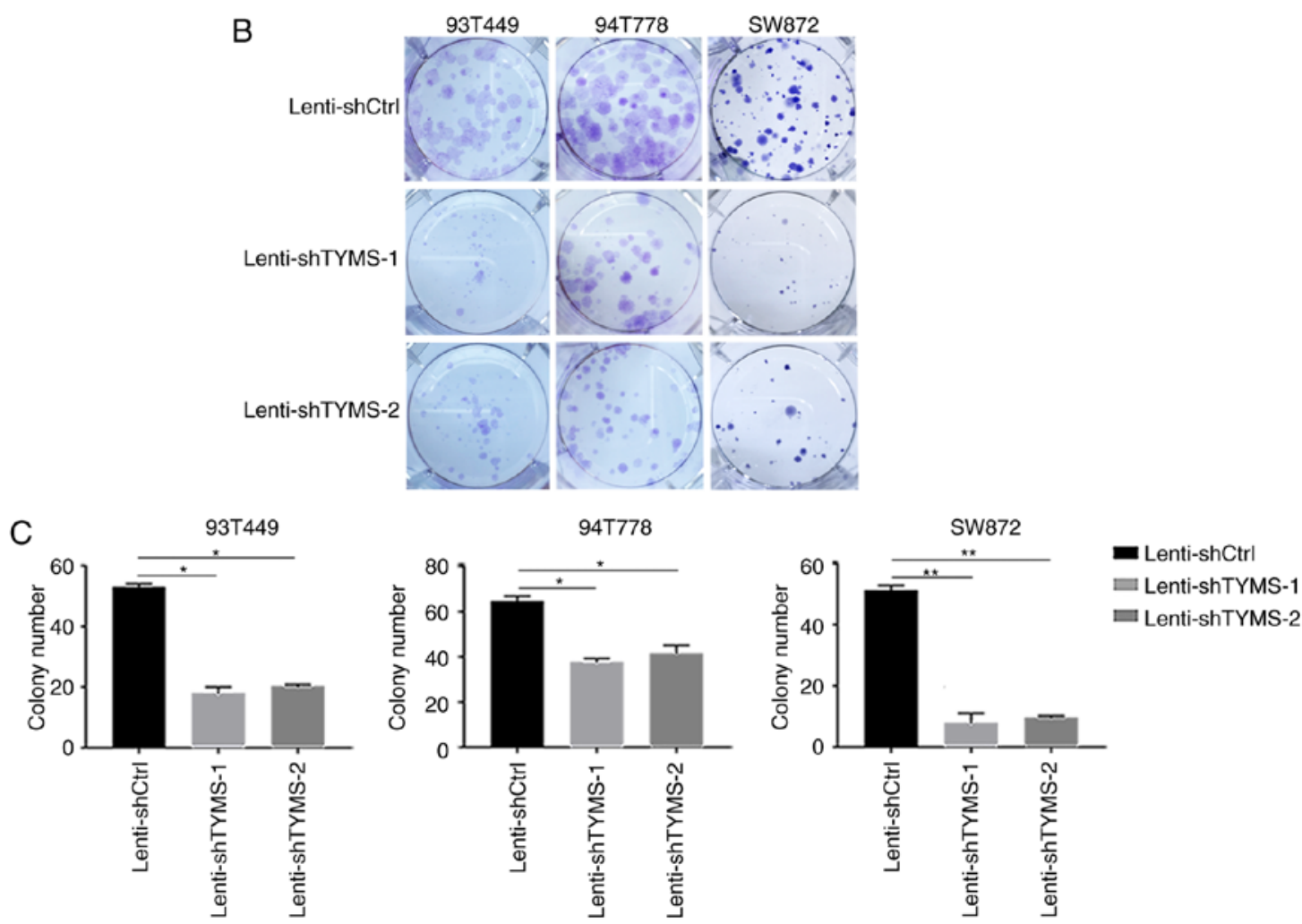

Figure 2. Knockdown of TYMS decreases the proliferation of RLPS cells. (A) The results of the Cell Counting Kit-8 assays showed that the downregulation of TYMS inhibited RLPS cell proliferation significantly in 93T449, 94T778 and SW872 cells. ${ }^{* * *} \mathrm{P}<0.01{ }^{* * * *} \mathrm{P}<0.001$. (B and C) Knockdown of TYMS expression decreased colony-forming capacity of the three cell lines. ${ }^{*} \mathrm{P}<0.05 .{ }^{* *} \mathrm{P}<0.01$. TYMS, thymidylate synthase; RLPS, retroperitoneal soft tissue sarcoma; sh, short hairpin.

with sarcoma and TYMS-high expression had lower OS and DFS time compared with those with TYMS-low expression (Fig. S3A and B; OS, P=0.0065; DFS, $\mathrm{P}=0.019$ ). The aforementioned results showed that high TYMS expression was associated with progression of RLPS or sarcoma.

Expression of TYMS in RLPS cell lines. Protein expression of TYMS was evaluated by western blotting in three human RLPS cell lines (93T449, 94T778 and SW872). The TYMS protein levels were considerably high in all three RLPS cell lines, particularly in the 93T449 and SW872 (Fig. S4A). TYMS was found to be localized in the cytoplasm in all three human RLPS cell lines (Fig. S4B). Therefore, all three cell lines were used for subsequent experiments.

Knockdown of TYMS expression reduces RLPS cell proliferation and colony formation, and promotes apoptosis. To examine the role of TYMS in RLPS cells, 93T449, 94T778 and SW872 cells were transfected with lentiviral vectors containing non-specific shRNA (Lenti-shCtrl) and shRNAs targeting TYMS (Lenti-shTYMS-1 and Lenti-shTYMS-2).
The transfection efficiency was confirmed using RT-qPCR and western blotting (Fig. S4C and D). The results of a CCK-8 assay showed that TYMS downregulation significantly reduced cell viability (Fig. $2 \mathrm{~A} ; \mathrm{P}<0.01$ ) and decreased colony-forming capacity (Fig. 2B and $\mathrm{C} ; \mathrm{P}<0.05$ ) in all three RLPS cell lines. To evaluate the apoptotic status of cell lines following knockdown of TYMS, TUNEL staining was performed on the RLPS cell lines. Lenti-shTYMS cells showed a significant increase in apoptosis compared with the Lenti-shCtrl transfected cells (Fig. S5).

Knockdown of TYMS promotes progression of the cell cycle from $G_{1}$ to $S$ phase. TYMS downregulation decreased cell proliferation, therefore, cycle cell distribution was assessed to determine whether this attenuation was associated with cell cycle arrest. Flow cytometry analysis demonstrated that TYMS knockdown promoted progression of the cell cycle from $\mathrm{G}_{1}$ to $\mathrm{S}$ phase. As shown in Fig. $3 \mathrm{~A}$ and $\mathrm{B}$, in $93 \mathrm{~T} 449$ cells, the proportion of cells in the $\mathrm{G}_{1}$ phase decreased significantly, from $88.05 \pm 1.01 \%$ in Lenti-shCtrl cells to $84.64 \pm 0.42 \%$ and $84.79 \pm 0.40 \%$ in Lenti-shTYMS-1 and Lenti-shTYMS-2 cells, respectively (both $\mathrm{P}<0.05$ ). The proportion of $\mathrm{S}$ phase cells 
A
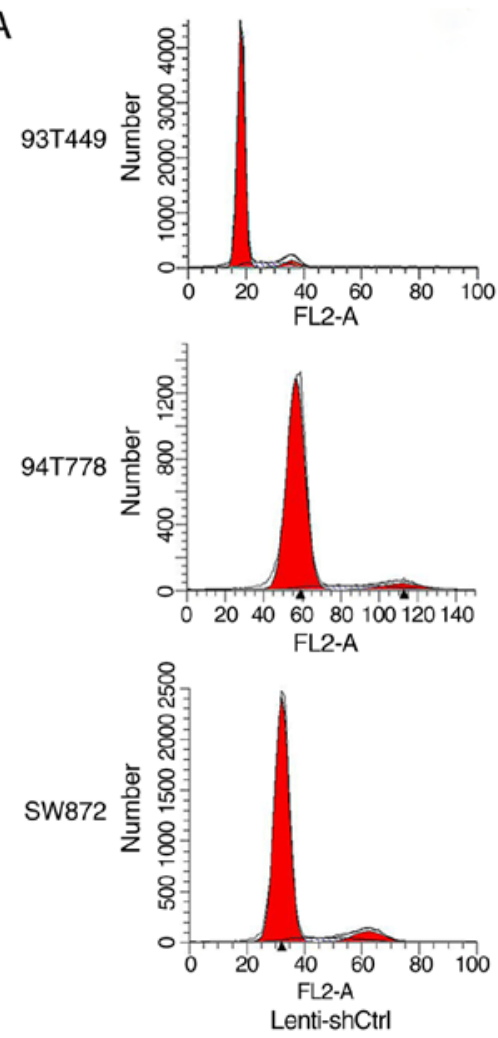
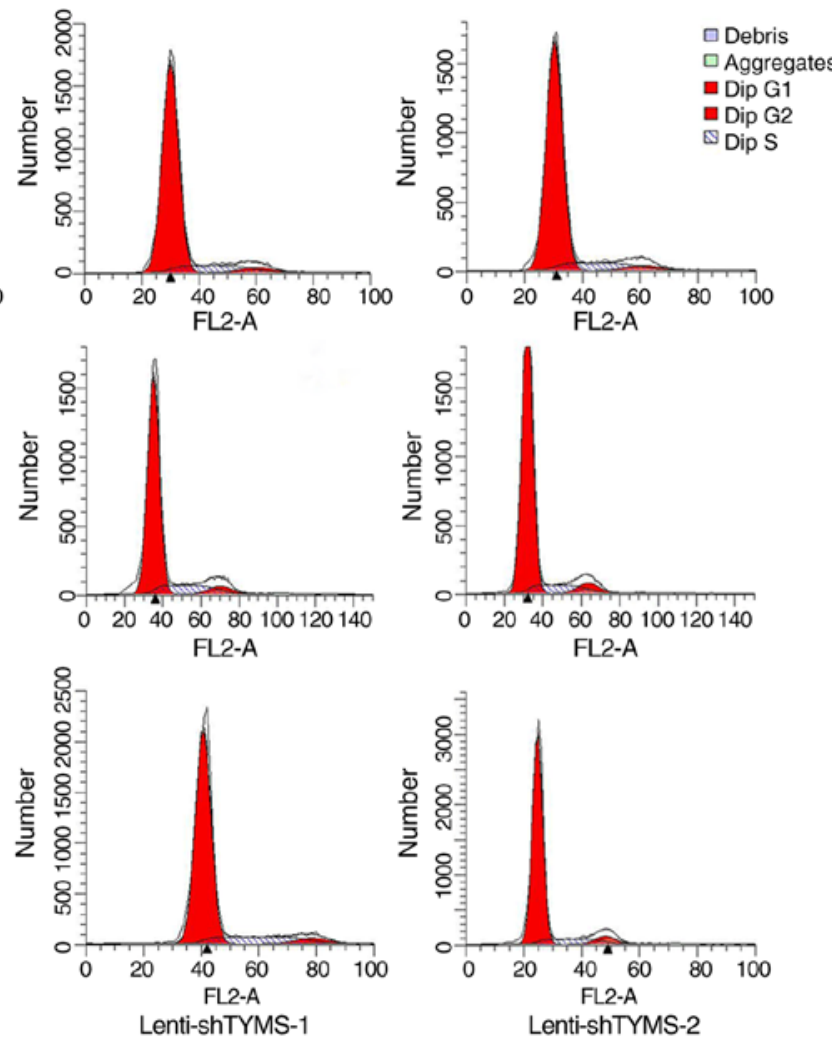

B
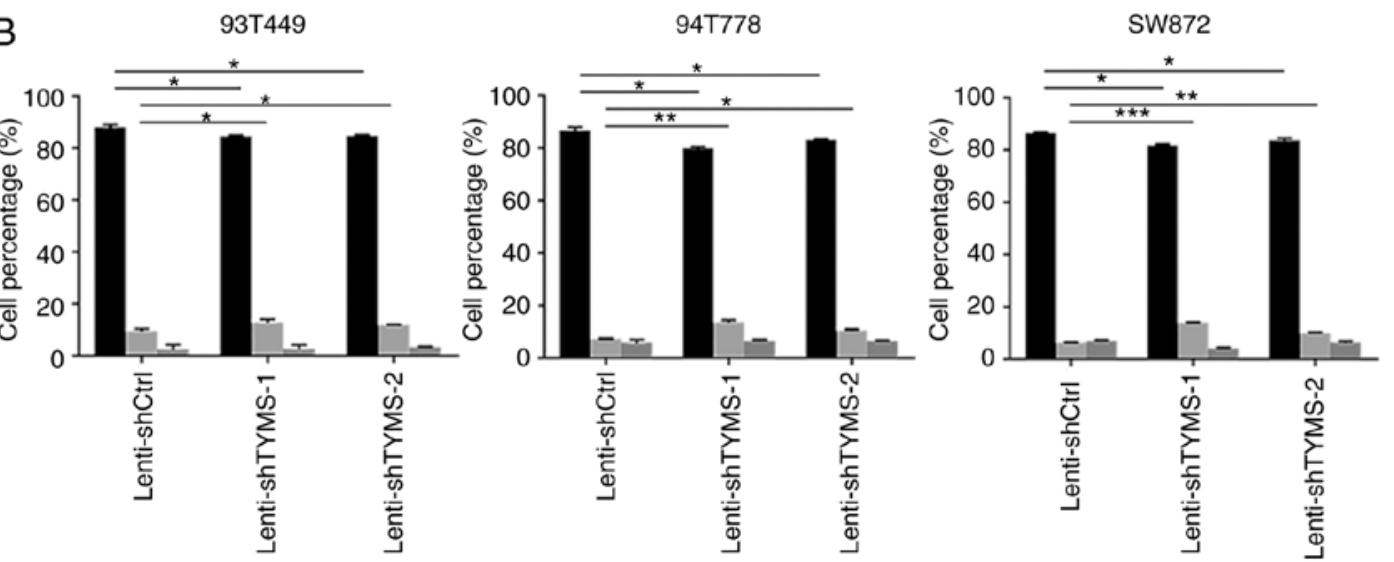

Figure 3. TYMS knockdown promotes progression of the cell cycle from the $\mathrm{G}_{1}$ phase to the $\mathrm{S}$ phase. (A) Cell cycle analysis showed that the proportion of $\mathrm{G}_{1}$ phase cells decreased and the proportion of $\mathrm{S}$ phase cells increased significantly in cells infected with Lenti-shTYMS compared with the control cells. (B) Quantitative analysis of cell cycle distribution. In $93 \mathrm{~T} 449$ cells, the proportion of cells at the $\mathrm{G}_{1}$ phase decreased significantly from $88.05 \pm 1.01 \%$ in Lenti-shCtrl cells to $84.64 \pm 0.42 \%$ and $84.79 \pm 0.40 \%$ in Lenti-shTYMS-1 and Lenti-shTYMS-2 cells, respectively. ${ }^{*} \mathrm{P}<0.05$. The proportion of S phase cells increased significantly from $9.52 \pm 0.86 \%$ in Lenti-shCtrl cells to $12.75 \pm 1.17 \%$ and $11.91 \pm 0.12 \%$ in Lenti-shTYMS- 1 and Lenti-shTYMS-2 cells, respectively. "P<0.05. In 94T778 cells, the proportion of cells at the G1 phase decreased significantly from $86.76 \pm 1.22 \%$ in Lenti-shCtrl cells to $79.90 \pm 0.67 \%$ and $83.10 \pm 0.48 \%$ in Lenti-shTYMS-1 and Lenti-shTYMS-2 cells, respectively. "P $<0.05$. The proportion of $\mathrm{S}$ phase cells increased significantly from $7.39 \pm 0.13 \%$ in Lenti-shCtrl cells to $13.68 \pm 0.8 \%$ and $10.47 \pm 0.53 \%$ in Lenti-shTYMS-1 and Lenti-shTYMS-2 cells, respectively. ${ }^{*} \mathrm{P}<0.05$. ${ }^{* *} \mathrm{P}<0.01$. In SW872 cells, the proportion of cells at the $\mathrm{G}_{1}$ phase decreased significantly from $86.65 \pm 0.32 \%$ in Lenti-shCtrl cells to $81.87 \pm 0.59 \%$ and $83.72 \pm 0.91 \%$ in Lenti-shTYMS-1 and Lenti-shTYMS-2 cells, respectively. ${ }^{*} \mathrm{P}<0.05$. The proportion of S phase cells increased significantly from $6.39 \pm 0.12 \%$ in Lenti-shCtrl cells to $14.00 \pm 0.22 \%$ and $9.87 \pm 0.45 \%$ in Lenti-shTYMS-1 and Lenti-shTYMS-2 cells, respectively. ${ }^{* *} \mathrm{P}<0.01{ }^{* * * *} \mathrm{P}<0.001$. TYMS, thymidylate synthase; sh, short hairpin.

increased significantly. Similar results were observed in the $94 \mathrm{~T} 778$ and SW872 cells. These results suggest that TYMS downregulation arrests the cell cycle at the $\mathrm{S}$ phase.

Downregulation of TYMS expression inhibits migration and invasion of RLPS cells. In order to determine the effect of TYMS expression on cell migration and invasion, Transwell migration and invasion assays were performed. As shown in Fig. 4, in 93T449 cells, the number of migrated cells per field was $95 \pm 35$ in shTYMS-1 cells $(\mathrm{P}<0.001)$ and $102 \pm 10$ in shTYMS- 2 cells $(\mathrm{P}<0.001)$ vs. $1,234 \pm 114$ in the control cells; the number of invaded cells per field was $118 \pm 11$ in shTYMS-1 cells $(\mathrm{P}<0.001)$ and $124 \pm 21$ in shTYMS-2 cells $(\mathrm{P}<0.001)$ vs. $849 \pm 71$ in control cells. Similar results were obtained in $94 \mathrm{~T} 778$ and SW872 cells. The results showed that TYMS knockdown significantly decreased both the migration and invasive capacities of RLPS cells, thereby indicating that TYMS downregulation may inhibit RLPS progression. 

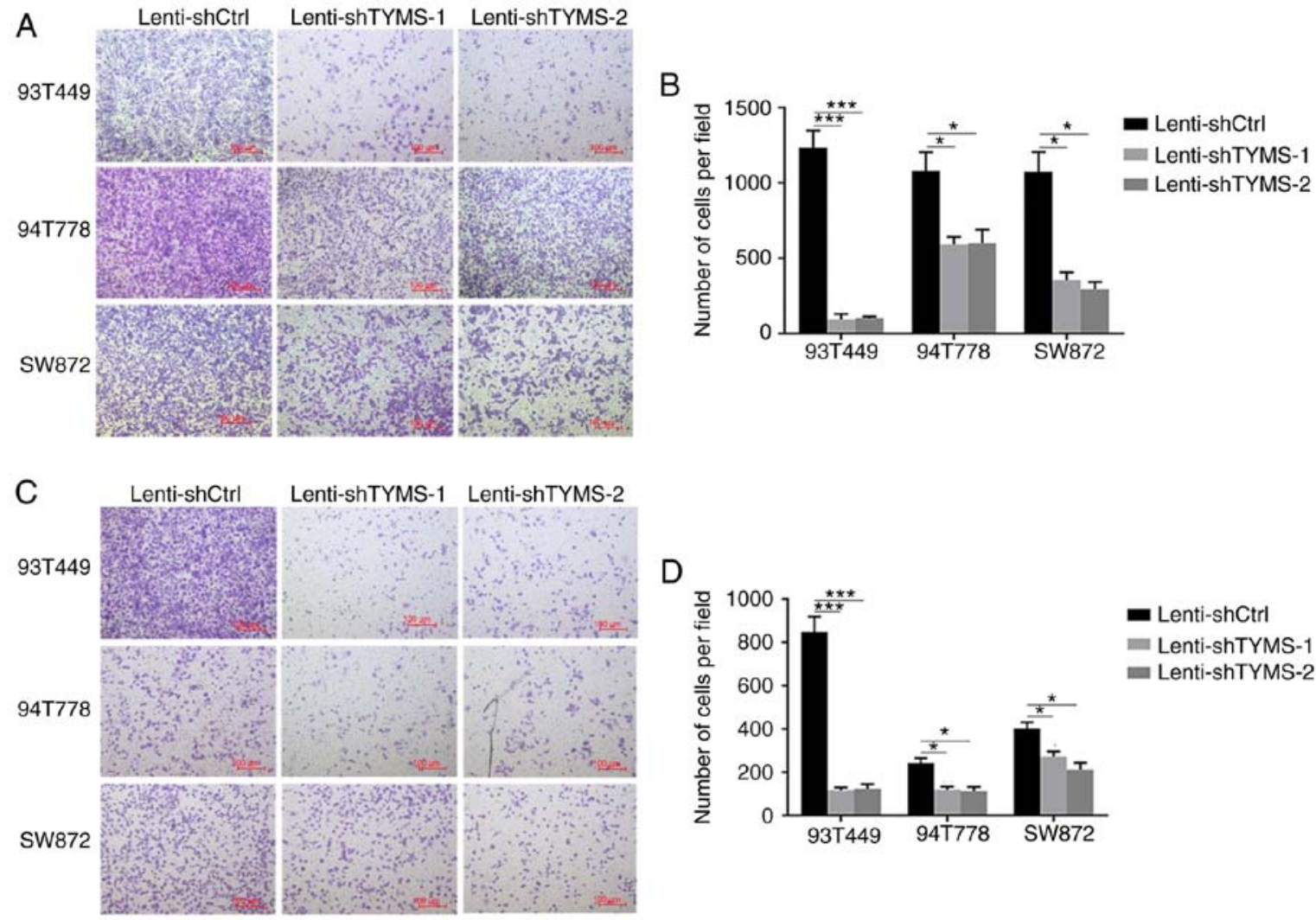

Figure 4. Knockdown of TYMS decreases migration and invasion of RLPS cells. Transwell migration and invasion assays were used to assess the migratory and invasive capacity of RLPS cells. The cells in five randomly selected fields were counted and statistically analyzed. (A and B) The number of migrated cells per field was fewer in Lenti-shTYMS cells compared with Lenti-shCtrl cells of 93T449, 94T778 and SW872 cells. (C and D) The number of invaded cells per field was fewer in Lenti-shTYMS cells compared with Lenti-shCtrl cells of 93T449, $94 \mathrm{~T} 778$ and SW872 cells. ${ }^{*} \mathrm{P}<0.05$. ${ }^{* * *} \mathrm{P}<0.001$. Scale bar, $100 \mu \mathrm{m}$. TYMS, thymidylate synthase; RLPS, retroperitoneal soft tissue sarcoma; sh, short hairpin.

TYMS knockdown may result in reduced activity of the JAK/STAT signaling pathway in RLPS cells. The aforementioned results suggest that TYMS serves an important role in the development and progression of RLPS; however, the mechanism is unclear. Thus the possible mechanisms of TYMS in RLPS cells (94T778 and SW872) were assessed using protein microarray analysis. The results showed that phospho-STAT3 (Ser727), phospho-STAT5 (Y694) and phospho-STAT6 (Y641) were downregulated in Lenti-shTYMS transfected 94T778 and SW872 cells (Fig. S6). Therefore, it was hypothesized that TYMS knockdown may have resulted in decreased activity of the JAK/STAT signaling pathway. Western blotting was used to assess the expression levels of major proteins associated with the JAK/STAT signaling pathway in Lenti-shCtrl and Lenti-shTYMS cells, including total Jak1-3 and Tyk 2 of the JAK family and the corresponding phosphorylated proteins, as well as the expression levels of total STAT1, STAT3, STAT5 and STAT6, and the corresponding phosphorylated proteins of the STAT family. The results showed that TYMS knockdown resulted in downregulation of the expression of phosphorylated Tyk2 in Lenti-shTYMS cells compared with the control cells, and the expression of phosphorylated Jak1, total Jak2, phosphorylated Jak2, total Jak3 and phosphorylated Jak3 were not detected. Meanwhile, phosphorylated STAT1 (Tyr701), phosphorylated STAT3 (Ser727), phosphorylated STAT5 (Y694) and phosphorylated STAT6 (Y641) in the STAT family were significantly downregulated in Lenti-shTYMS cells, consistent with the results of protein microarray analysis (Fig. 5; Fig. S7). These results suggest that TYMS knockdown may downregulate the activity of the JAK/STAT signaling pathway in RLPS cells, thereby inhibiting the progression of RLPS.

\section{Discussion}

Complete surgical resection is the most effective treatment for RLPS (3). However, local recurrence is frequently observed, and $\sim 70 \%$ of RLPS-associated deaths occur without distant metastasis despite surgical resection, highlighting the need for effective therapeutic targets and combinative treatments (4). In the present study, the microarray expression data between LPS and NF samples were compared, and 855 DEGs were identified (334 upregulated and 521 downregulated genes). Subsequently, HCS was used to evaluate the effect of the genes that exhibited high expression on the proliferative ability of RLPS cells to determine the functional genes with a strong influence on the progression of RLPS. Since HCS is a preliminary screening tool, separate transfection controls were not performed for each gene presented in Fig. 1C, and this is the usual practice when using the HCS technology. Among the DEGs that were assessed in the HCS experiments, TYMS showed the most notable effect, and was thus used for all subsequent experiments in RLPS tissues and in vitro.

TYMS is an essential enzyme involved in DNA replication and repair, which serves an important role in the biosynthesis 

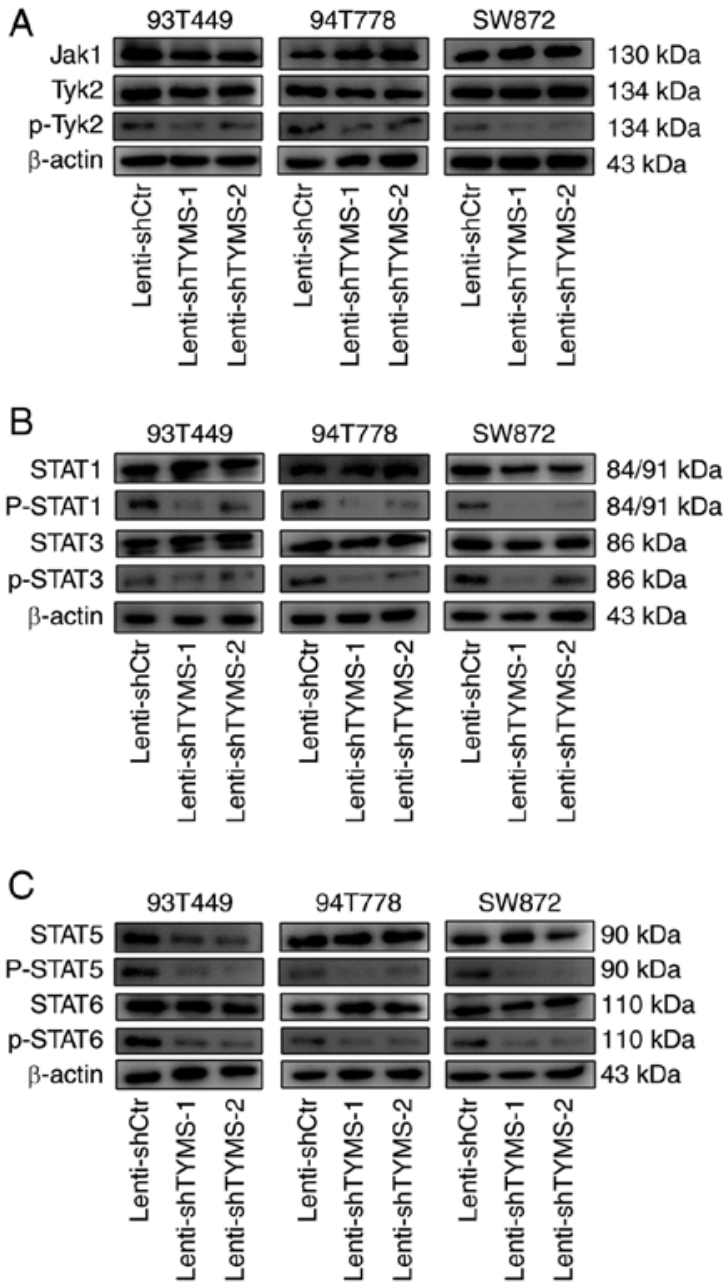

Figure 5. The JAK/STAT signaling pathway is downregulated after TYMS knockdown in RLPS cells. (A) Phospho-Tyk2 expression, in the JAK family, was downregulated in Lenti-shTYMS cells compared with control cells. (B) Phospho-STAT1 (Tyr701) and phospho-STAT3 (Ser727) expression, in the STAT family, were downregulated in Lenti-shTYMS cells (C) Phospho-STAT5 (Y694) and phospho-STAT6 (Y641) expression, in the STAT family, were downregulated in Lenti-shTYMS cells. TYMS, thymidylate synthase; sh, short hairpin; RLPS, retroperitoneal soft tissue sarcoma; JAK/STAT, Janus kinase/signal transducers and activators of transcription.

of deoxythymidine monophosphate (dTMP) (17). The association between TYMS and tumors has been reported previously. TYMS overexpression is associated with poor disease-specific survival, poor local recurrence-free survival and other adverse clinical behaviors in various solid tumors, such as nasopharyngeal carcinoma (18), lung cancer (19), gastric cancer (20), mesothelioma (21) and prostate cancer (22). TYMS can be a useful biomarker for predicting 5-fluorouracil (5-FU) resistance, if expression is analyzed in circulating tumor cells, and the expression levels of intra-tumoral TYMS mRNA (paraffin-embedded tissue) can independently predict the survival of patients with metastatic colorectal cancer treated with 5-FU and oxaliplatin (23). In addition, TYMS is a malignant tumor marker with a high degree of specificity and sensitivity for the metastasis of low-grade glioma (24). In HLA-A2(+) colon cancer, TYMS may serve as an appropriate target for specific immunotherapy (25).

In the present study, relative mRNA expression of TYMS was notably higher in RLPS tissues compared with NF tissues.
TYMS protein expression was assessed in RLPS samples and the results showed its expression was present in the majority of samples (74.5\%). For patients with well-differentiated, dedifferentiated, myxoid/round cell and pleomorphic subtypes, TYMS was $42.9,91.3,80.0$ and $80.0 \%$ positive, respectively $(\mathrm{P}=0.009)$. The expression of TYMS was higher in patients with high-grade RLPS $(P=0.003)$. Additionally, survival analysis showed a significant negative association between TYMS expression and survival (OS and DFS) of patients with RLPS. Furthermore, survival analysis of TYMS and sarcoma using GEPIA database also showed that patients with sarcoma and TYMS-high expression had poorer survival (OS and DFS) compared with those with TYMS-low expression, consistent with the results of tissue expression analysis, together suggesting that high expression of TYMS may be an adverse factor for post-operative survival of patients with RLPS or sarcoma.

CCK-8 and colony-formation assays demonstrated that downregulation of TYMS may inhibit the proliferation of RLPS in vitro. Consistent with the present study, several studies also reported that downregulation or inhibition of TYMS reduced proliferation, such as in mesothelioma, bladder cancer, colorectal cancer and glioblastoma $(21,26-28)$.

Ligabue et al (29), showed that inhibition of TYMS significantly interfered with cell cycle progression in ovarian cystadenocarcinoma cells, resulting in the accumulation of cells in the $\mathrm{S}$ phase and a substantial decrease in cells in the $\mathrm{G}_{0}-\mathrm{G}_{1}$ phase and $\mathrm{G}_{2}-\mathrm{M}$ phases. The findings of the present study showed that downregulation of TYMS promoted cell transition from $G_{1}$ to $S$ phase, consistent with the study by Ligabue et al (29). Furthermore, migration and invasion of cells with TYMS expression knocked down was decreased compared with the control cells. Together, the results suggest that TYMS inhibition may slow down the progression of RLPS.

Following TYMS knockdown, protein microarray analysis was performed. Since protein microarray analysis is a preliminary tool for pathway study, it is the usual practice for not analyzing the respective non-phosphorylated proteins of phosphorylated proteins. From the protein microarray analysis results, it was shown that activity of the JAK/STAT signaling pathway was downregulated in RLPS cells. Cytokines bind to their cytokine receptors and induce conformational changes, resulting in receptor dimerization-JAK tyrosine phosphorylation. This effect generates docking sites for STATs, leading to STAT phosphorylation with the phosphorylated dimers acting as transcription factors. The JAK/STAT pathway is one of the major signaling cascades, which mediates cytokine receptor-derived signaling, and serves a role in hematopoietic cell proliferation and differentiation. Multiple hematological malignancies exhibit inappropriate activation of the JAK signaling pathway, as a result of a variety of mechanisms, including the downregulation of negative regulators, activating mutations and fusions (30). Activation of the JAK/STAT pathway is a major carcinogenic event in human liver cancer (31). The results of the present study showed that downregulation of TYMS expression may result in the downregulation of the activity of JAK/STAT signaling pathway in RLPS cells. In agreement with this, it was previously reported that inhibition of the JAK/STAT pathway reduced cell proliferation and induced apoptosis in cutaneous 
T-cell lymphomas (32). In addition, small molecule inhibitors targeting the JAK/STAT pathway effectively decreased cell proliferation in Akt/ $\beta$-catenin-driven HCC (31).

The results of the protein microarray analysis showed increased expression of phosphorylated P53 following TYMS knockdown. Two previous studies demonstrated that the p53-dependent response limited the viability of mammalian haploid cells, likely by increasing cell apoptosis, and p53 deletion increased the viability and proliferation of the haploid cells $(33,34)$. This suggests that decreased RLPS cell viability and increased apoptosis, following TYMS knockdown may be associated with an increase in P53. Thus, future studies are required to explore the association between P53 and TYMS.

In the present study, shRNA mediated knockdown of TYMS did not result in a complete silencing of TYMS expression at the protein level. Knocking out target genes in haploid embryonic stem cells not only results in complete silencing at the mRNA level, but also guarantees that mutations, which only affected one set of chromosomes carried by haploid cells, are represented in the corresponding phenotypes (35). Thus, in future studies, the functions of TYMS and the role of JAK/STAT pathway using haploid cells and more robust gene knockout techniques will be assessed.

To the best of our knowledge, the present study is the first to examine the effects of TYMS on the biological behaviors of RLPS cells and the underlying mechanisms. Additionally, it was demonstrated that downregulation of TYMS decreased biological behaviors of RLPS cells, likely through downregulation of the JAK/STAT signaling pathway activity. However, there are still some limitations in the present study. Overexpression of TYMS in TYMS knockdown cell lines and their effect on rescuing the results should be conducted in order to further verify the role of TYMS in RLPS. Additionally, the deeper mechanisms underlying the effect of TYMS on the JAK/STAT signaling pathway in RLPS will be further investigated in vitro and in vivo. As many other genes were screened, it is intended to examine their effects more extensively in future studies, in order to fully elucidate the pathogenesis of RLPS.

In conclusion, the results of the present study showed that TYMS was overexpressed in RLPS tissues, and downregulation of TYMS inhibited tumor progression, likely through downregulation of the JAK/STAT signaling pathway in RLPS, using bioinformatics analysis and biological verification. Therefore, TYMS may be used as a potential effective therapeutic target for the treatment of RLPS by using specific inhibitors. In addition, targeting the JAK/STAT pathway may also serve as a promising strategy for the treatment of RLPS.

\section{Acknowledgements}

Not applicable.

\section{Funding}

This study was supported by Beijing Municipal Administration of Hospital's Ascent Plan (grant no. DFL20181104); Beijing Municipal Natural Science Foundation (grant no. Z190022 and 7153161); Beijing Municipal Administration of Hospitals' Youth Programme (grant no. QML20181104); Beijing Municipal
Administration of Hospitals Clinical Medicine Development of Special Funding Support (grant no. XMLX201708); the Capital Health Research and Development of Special Funds (grant no. 2020-1-1021); and the National Natural Science Funding (grant no. 31770836).

\section{Availability of data and materials}

The datasets used and/or analyzed during the present study are available from the corresponding author on reasonable request.

\section{Authors' contributions}

SZ performed the experimental operation, data collection, data analysis and was a major contributor in writing the manuscript. CYH and XYT conceived the study and revised the manuscript. $\mathrm{LY}, \mathrm{CC}$ and $\mathrm{ZW}$ performed acquisition and analysis of data. JHW and XYG collected the specimens used in the study. MZ and BD prepared and visualized the slices. All authors read and approved the final manuscript. All authors read and approved the final version of the manuscript.

\section{Ethics approval and consent to participate}

This study was approved by the Ethics Committee of Peking University Cancer Hospital (approval no. 2019KT19) and written informed consent was obtained from each participant.

\section{Patient consent for publication}

Not applicable.

\section{Competing interests}

The authors declare that they have no competing interests.

\section{References}

1. Messiou C, Moskovic E, Vanel D, Morosi C, Benchimol R, Strauss D, Miah A, Douis H, van Houdt W and Bonvalot S: Primary retroperitoneal soft tissue sarcoma: Imaging appearances, pitfalls and diagnostic algorithm. Eur J Surg Oncol 43: 1191-1198, 2017.

2. Vijay A and Ram L: Retroperitoneal liposarcoma: A comprehensive review. Am J Clin Oncol 38: 213-219, 2015.

3. Paloyo SR, Ramirez AD, David-Paloyo FP and Dofitas RB: Wide excision of a retroperitoneal liposarcoma with en bloc ureterectomy and renal salvage by autotransplantation. Case Rep Transplant 2019: 9725169, 2019.

4. Bagaria SP, Gabriel E and Mann GN: Multiply recurrent retroperitoneal liposarcoma. J Surg Oncol 117: 62-68, 2018.

5. Molina G, Hull MA, Chen YL, DeLaney TF, De Amorim Bernstein K, Choy E, Cote G, Harmon DC, Mullen JT and Haynes AB: Preoperative radiation therapy combined with radical surgical resection is associated with a lower rate of local recurrence when treating unifocal, primary retroperitoneal liposarcoma. J Surg Oncol 114: 814-820, 2016.

6. Mansfield SA, Pollock RE and Grignol VP: Surgery for abdominal well-differentiated liposarcoma. Curr Treat Options Oncol 19: 1, 2018.

7. Cheng W, Ren X, Zhang C, Cai J, Liu Y, Han S and Wu A: Bioinformatic profiling identifies an immune-related risk signature for glioblastoma. Neurology 86: 2226-2234, 2016.

8. Lin $\mathrm{H}$, Zhang Q, Li X, Wu Y, Liu Y and Hu Y: Identification of key candidate genes and pathways in hepatitis B virus-associated acute liver failure by bioinformatical analysis. Medicine (Baltimore) 97: e9687, 2018. 
9. Guo Y, Bao Y, Ma M and Yang W: Identification of key candidate genes and pathways in colorectal cancer by integrated bioinformatical analysis. Int J Mol Sci 18: 722, 2017.

10. Lee S and Howell BJ: High-content screening: Emerging hardware and software technologies. Methods Enzymol 414: 468-483, 2006.

11. Barretina J, Taylor BS, Banerji S, Ramos AH, Lagos-Quintana M, Decarolis PL, Shah K, Socci ND, Weir BA, Ho A, et al: Subtype-specific genomic alterations define new targets for soft-tissue sarcoma therapy. Nat Genet 42: 715-721, 2010.

12. Irizarry RA, Hobbs B, Collin F, Beazer-Barclay YD, Antonellis KJ, Scherf U and Speed TP: Exploration, normalization, and summaries of high density oligonucleotide array probe level data. Biostatistics 4: 249-264, 2003.

13. Wettenhall JM and Smyth GK: limmaGUI: A graphical user interface for linear modeling of microarray data. Bioinformatics 20: 3705-3706, 2004.

14. Benjamini $\mathrm{Y}$ and Hochberg Y: Controlling the false discovery rate: A practical and powerful approach to multiple testing. J R Stat Soc B (Methodological) 57: 289-300, 1995.

15. Tang S, Jing H, Huang Z, Huang T, Lin S, Liao M and Zhou J: Identification of key candidate genes in neuropathic pain by integrated bioinformatic analysis. J Cell Biochem 121: 1635-1648, 2020.

16. Livak KJ and Schmittgen TD: Analysis of relative gene expression data using real-time quantitative PCR and the 2(-Delta Delta $\mathrm{C}(\mathrm{T}))$ method. Methods 25: 402-408, 2001.

17. Balboa-Beltrán E, Duran G, Lamas MJ, Carracedo A and Barros F: Long survival and severe toxicity under 5-fluorouracil-based therapy in a patient with colorectal cancer who harbors a germline codon-stop mutation in TYMS. Mayo Clin Proc 90: 1298-1303, 2015.

18. Lee SW, Chen TJ, Lin LC, Li CF, Chen LT, Hsing CH, Hsu HP, Tsai CJ, Huang HY and Shiue YL: Overexpression of thymidylate synthetase confers an independent prognostic indicator in nasopharyngeal carcinoma. Exp Mol Pathol 95: 83-90, 2013.

19. Lam SK, Mak JC, Zheng CY, Li YY, Kwong YL and Ho JC: Downregulation of thymidylate synthase with arsenic trioxide in lung adenocarcinoma. Int J Oncol 44: 2093-2102, 2014.

20. Formentini A, Henne-Bruns D and Kornmann M: Thymidylate synthase expression and prognosis of patients with gastrointestinal cancers receiving adjuvant chemotherapy: A review. Langenbecks Arch Surg 389: 405-413, 2004.

21. Lam SK, Li YY, Zheng CY and Ho JC: Downregulation of thymidylate synthase and E2F1 by arsenic trioxide in mesothelioma. Int J Oncol 46: 113-122, 2015.

22. Burdelski C, Strauss C, Tsourlakis MC, Kluth M, Hube-Magg C, Melling N, Lebok P, Minner S, Koop C, Graefen M, et al: Overexpression of thymidylate synthase (TYMS) is associated with aggressive tumor features and early PSA recurrence in prostate cancer. Oncotarget 6: 8377-8387, 2015.

23. Abdallah EA, Fanelli MF, Buim ME, Machado Netto MC, Gasparini Junior JL, Souza E, Silva V, Dettino AL, Mingues NB, Romero JV, et al: Thymidylate synthase expression in circulating tumor cells: A new tool to predict 5-fluorouracil resistance in metastatic colorectal cancer patients. Int J Cancer 137: 1397-1405, 2015.

24. Ding B, Gao M, Li Z, Xu C, Fan S and He W: Expression of TYMS in lymph node metastasis from low-grade glioma. Oncol Lett 10: 1569-1574, 2015.
25. Shichijo S, Azuma K, Komatsu N, Ito M, Maeda Y, Ishihara Y and Itoh K: Two proliferation-related proteins, TYMS and PGK1, could be new cytotoxic $\mathrm{T}$ lymphocyte-directed tumor-associated antigens of HLA-A2+ colon cancer. Clin Cancer Res 10: 5828-5836, 2004.

26. Mpindi JP, Sara H, Haapa-Paananen S, Kilpinen S, Pisto T, Bucher E, Ojala K, Iljin K, Vainio P, Björkman M, et al: GTI: A novel algorithm for identifying outlier gene expression profiles from integrated microarray datasets. PLoS One 6: e17259, 2011.

27. Abu Lila AS, Moriyoshi N, Fukushima M, Huang CL, Wada $H$ and Ishida T: Metronomic S-1 dosing and thymidylate synthase silencing have synergistic antitumor efficacy in a colorectal cancer xenograft model. Cancer Lett 400: 223-231, 2017.

28. Ide H, Kikuchi E, Hasegawa M, Hattori S, Yasumizu Y, Miyajima A and Oya M: Therapeutic enhancement of S-1 with CPT-11 through down-regulation of thymidylate synthase in bladder cancer. Cancer Med 2: 488-495, 2013.

29. Ligabue A, Marverti G, Liebl U and Myllykallio H: Transcriptional activation and cell cycle block are the keys for 5-fluorouracil induced up-regulation of human thymidylate synthase expression. PLoS One 7: e47318, 2012.

30. Maude SL, Dolai S, Delgado-Martin C, Vincent T, Robbins A, Selvanathan A, Ryan T, Hall J, Wood AC, Tasian SK, et al: Efficacy of JAK/STAT pathway inhibition in murine xenograft models of early T-cell precursor (ETP) acute lymphoblastic leukemia. Blood 125: 1759-1767, 2015.

31. Toh TB, Lim JJ, Hooi L, Rashid M and Chow EK: Targeting Jak/Stat pathway as a therapeutic strategy against SP/CD44+ tumorigenic cells in Akt/ $\beta$-catenin-driven hepatocellular carcinoma. J Hepatol 72: 104-118, 2020.

32. Yang H, Ma P, Cao Y, Zhang M, Li L, Wei J, Tao L and Qian K: ECPIRM, a potential therapeutic agent for cutaneous T-cell lymphoma, inhibits cell proliferation and promotes apoptosis via a JAK/STAT pathway. Anticancer Agents Med Chem 18: 401-411, 2018.

33. Olbrich T, Mayor-Ruiz C, Vega-Sendino M, Gomez C, Ortega S, Ruiz S and Fernandez-Capetillo O: A p53-dependent response limits the viability of mammalian haploid cells. Proc Natl Acad Sci USA 114: 9367-9372, 2017.

34. Peng K, Li X, Wu C, Wang Y, Yu J, Zhang J, Gao Q, Zhang W, Zhang Q, Fan Y, et al: Derivation of haploid trophoblast stem cells via conversion in vitro. iScience 11: 508-518, 2019.

35. Li Y and Shuai L: A versatile genetic tool: Haploid cells. Stem Cell Res Ther 8: 197, 2017.

36. Fletcher CDM, Bridge JA, Hogendoorn P and Mertens F (eds): World Health Organization, International Agency for Research on Cancer. WHO classification of tumours of soft tissue and bone. 4th edition. Lyon, IARC Press, 2013.

37. Trojani M, Contesso G, Coindre JM, Rouesse J, Bui NB, de Mascarel A, Goussot JF, David M, Bonichon F and Lagarde C: Soft-tissue sarcomas of adults; study of pathological prognostic variables and definition of a histopathological grading system. Int J Cancer 33: 37-42, 1984.

This work is licensed under a Creative Commons Attribution-NonCommercial-NoDerivatives 4.0 International (CC BY-NC-ND 4.0) License. 